\title{
The awareness of chronic obstructive pulmonary disease among smokers admitting to pulmonary medicine outpatient clinic: Single center experience
}

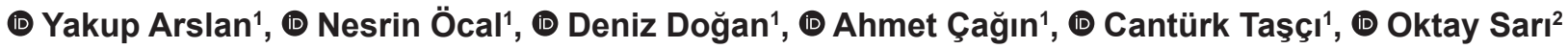 \\ 1 University of Health Sciences Turkey, Gülhane Training and Research Hospital, Clinic of Pulmonary Medicine, Ankara, Turkey \\ 2University of Health Sciences Turkey, Gülhane Training and Research Hospital, Clinic of Family Medicine, Ankara, Turkey
}

Date submitted:

16.11.2020

Date accepted:

03.01.2021

Online publication date:

15.03.2021

\section{Corresponding Author:}

Yakup Arslan Assistant Professor, University of Health Sciences Turkey, Gülhane Training and Research Hospital, Clinic of Pulmonary Medicine, Ankara, Turkey

yakuparslan75@yahoo.com

ORCID:

orcid.org/0000-0002-9079-1701

Keywords: Chronic obstructive pulmonary disease, COPD awareness level of smokers, COPD awareness survey, smoking cessation polyclinic

\begin{abstract}
Aims: Smoking is the strongest risk factor for chronic obstructive pulmonary disease (COPD), but the awareness of COPD among smokers has been found at low levels worldwide. The aim of current study was to assess the COPD awareness level among smokers and to determine the factors associated with awareness.

Methods: The current study involved the smokers admitted to the smoking cessation outpatient clinic, pulmonary medicine outpatient clinic, and pulmonary medicine clinic of an Training and Research Hospital. A self-administered COPD awareness survey was applied and the question of "Have you ever heard the term of COPD?" was asked to all participants. According to the survey scores, participants were categorized into groups as "Poor", "Good" and "Very Good" Awareness.
\end{abstract}

Results: All included 531 participants were asked the question of "Have you ever heard the term of COPD?", and 490 (92.3\%) of them answered that question as "Yes". Statistically significant differences were found between the participants saying "Yes" and those saying "No" in the terms of the age range, smoking status, and education status with the numbers and percentages of $117(23.87 \%), 246(50.2 \%)$, and 170 (34.69\%) ( $p=0.039, p<0.001$, and $p=0.004)$, respectively. The numbers and percentages of "Poor Awareness", "Good Awareness" and "Very Good Awareness" groups were 211 (39.75\%), 299 (56.3\%), and 21 (3.95\%), respectively.

Conclusions: The awareness level of COPD among smokers admitted to pulmonary medicine department was detected as "Good", and this "Good" level was predicted to be associated with the publicly sponsored broad anti-smoking campaigns including smoking cessation polyclinics offering free service.

\section{Introduction}

Chronic obstructive pulmonary disease (COPD) is a common, preventable and treatable disease that is characterized by persistent respiratory symptoms and airflow limitation due to airway and/or alveolar abnormalities. COPD is in close relationship with significant exposure to noxious particles, especially tobacco (1). With a prevalence of 5 to $14 \%$ in general population, COPD is currently the $4^{\text {th }}$ leading cause of death in the world but is projected to be the $3^{\text {rd }}$ leading cause of death by 2020 (2-7). The risk of developing COPD among smokers is more than $40 \%$ (8). In Turkey, the prevalence of tobacco smoking and COPD disease is $31.6 \%$ and $3.6 \%$, respectively (9).
COPD onset time for smokers has not been clear yet. COPD patients even if with an end-stage, may usually perceive their symptoms like dyspnea and weakness as an expected age-relevant condition rather than COPD (10). Additionally, it has been declared that, under or misdiagnosed percentages of COPD patients were very high $(8,11-13)$. The initial step of prevention and treatment for COPD is the awareness of this COPD disaster. Currently, no validated method and survey were defined to evaluate the awareness level of public and especially smokers on COPD (14-21).

In GARD study conducted to evaluate COPD awareness in general population of Turkey, it was observed that 
approximately half of the participants did not know that COPD was a lung disease and was associated with smoking (22). In a survey conducted in current smokers, results also showed that awareness was lower than expected in Turkey (23). However, especially in recent years, it is prospected that educational activities such as increasing social trainings, warnings on cigarette packs, public spots, smoke free zones and smoking cessation polyclinics may have changed this situation positively. With this point of view, in this current study, we aimed to reveal the awareness and knowledge of COPD in smokers. In this way, we aim to make awareness assessments especially for active smokers, who are the target audience, and to help to plan the appropriate measures and education programs with the results to be drawn from this study.

\section{Methods}

This study is a cross-sectional epidemiologic study performed in the Pulmonary Medicine Department of University of Health of Sciences Turkey, Gülhane Training and Research Hospital (Ankara, Turkey) between the dates of May 01, 2018 and December 31, 2019. Current smokers admitted to the Smoking Cessation Outpatient Clinic and Pulmonary Medicine Outpatient Clinic were invited to participate in this current survey. The volunteer participants were applied to self-administered questionnaire that consisted of three different sections with the titles of $A, B$ and $C$.

Section A: The personal data including age, gender, body mass index, education status, occupation, clinical findings such as symptoms (cough, dyspnea, etc.) and symptom score of dyspnea in accordance with the Modified Medical Research Council scale of the participants were gathered.

Overall tobacco exposure burden of the participants was assessed by package/year ( $\mathrm{p} / \mathrm{y})$ calculation, and the nicotine addiction level was evaluated with the Fagerström Test for Nicotine Dependence Test Score (FTND). Participants were defined as "mild", "moderate" and "severe" smokers according to the tobacco exposure years of less than $10 \mathrm{p} / \mathrm{y}, 10-30 \mathrm{p} / \mathrm{y}$ and more than $30 \mathrm{p} / \mathrm{y}$, respectively. Participants were also grouped as mild, moderate and severe nicotine addicts according to their FTND scores (FTND $\leq 3,4-7$ and $\geq 8$, respectively).

Section B: The participants were asked whether they had ever heard about COPD and they had any information about COPD. Their information resources were also asked.

Section C: The participants were asked a 20 questionedCOPD Awareness Level Survey consisting of four different question concepts as the 'perception' episode including the questions numbers of 1, 2, 4, 5 and 6 , the 'knowledge' episode including the questions numbers of $3,7,16,17$ and 18 , the 'acceptance' episode including the questions numbers of 8 , 10, 11, 12 and 19 and the 'expectation' episode including the questions numbers of $9,13,14,15$ and 20 (Table 1). The distribution of episodes" questions was harmonized in order to provide answering without any bias.

The questions of survey were answered by participants as 'absolutely disagreed', 'disagreed', 'indecisive', 'agreed' and 'absolutely agreed'. Each question was scored with 1 to 5 points according to these answers (except for $13^{\text {th }}, 14^{\text {th }}$ and $17^{\text {th }}$ questions which were valued as absolutely disagreed as 5 points, disagreed as 4 points, indecisive as 3 points, agreed as 2 points and absolutely agreed as 1 point in order to reduce the predictability of the survey by the participant). This reversed valued questions helped to avoid the bias answering. The answers were reorganized into three groups as follows; the 'absolutely disagreed' and 'disagreed' were combined as 'disagreed participants', the 'absolutely agreed' and 'agreed' were combined as 'agreed participants' and 'indecisive' was presented as 'undecided participants. Then, Total Awareness Score was calculated by summing all the answer points for each participant. Considering the Total Awareness Scores, the participants were levelled into three groups named as "POOR", "GOOD" and "VERY GOOD" awareness with the total points of 0-69, 70-85 and 86-100, respectively.

Ethics committee approval was received for this study from the Ethics Committee of Gülhane Training and Research Hospital with the number of $18 / 111$ at April 24, 2018. Written informed consent was obtained from patients who participated in this study.

\section{Statistical Analysis}

Relationships of investigated parameters were evaluated statistically. SPSS for Mac 20.0 package program (SPSS Inc, Chicago, IL) was used for statistical evaluation. Data were summarized as the mean and standard deviation (SD) for the continuous variables, as absolute value and percentages for the categorical variables. The normality of the continuous variables was analyzed with the Kolmogorov-Smirnov test and Shapiro-Wilks test. Chi-square test for the categorical variables and Student's t-test or Mann-Whitney $U$ statistical tests were used according to the suitability to the normal distribution for the continuous variables. In the assessment of correlations, Spearman's correlation analysis was used for data with nonparametric distribution. $P$ value less than 0.05 was considered as statistically significant with a $95 \%$ confidence interval.

\section{Results}

A total of 531 [343 men (64.5\%), 188 women (35.5\%)] participants were enrolled to the study and all were applied the COPD Awareness Survey shown in Table 1. The participants were included from smoking cessation outpatient clinic, pulmonary medicine outpatient clinic and pulmonary medicine clinic with the numbers and percentages of 398 (75\%), 119 


\begin{tabular}{|c|c|c|c|c|c|}
\hline & \multicolumn{2}{|c|}{ Disagreed } & \multirow{2}{*}{$\begin{array}{l}\text { Indecisive } \\
\text { Indecisive }\end{array}$} & \multicolumn{2}{|c|}{ Agreed } \\
\hline & $\begin{array}{c}\text { Completely } \\
\text { Disagreed }\end{array}$ & Disagreed & & Agreed & $\begin{array}{c}\text { Completely } \\
\text { Agreed }\end{array}$ \\
\hline \multicolumn{6}{|l|}{ 1. COPD is a very frequent disease. } \\
\hline \multicolumn{6}{|l|}{ 2. COPD has a severe mortality rate. } \\
\hline \multicolumn{6}{|l|}{ 5. COPD is a preventable disease. } \\
\hline \multicolumn{6}{|l|}{ 6. COPD is a treatable disease. } \\
\hline \multicolumn{6}{|l|}{ 7. This disease develops with the obstruction of the airways. } \\
\hline \multicolumn{6}{|l|}{$\begin{array}{l}\text { 8. Exposure of non-smokers to cigarette smoke in a smoking } \\
\text { environment may cause COPD. }\end{array}$} \\
\hline \multicolumn{6}{|l|}{$\begin{array}{l}\text { 11. Exposure to organic and inorganic occupational dusts and } \\
\text { chemicals may cause COPD. }\end{array}$} \\
\hline \multicolumn{6}{|l|}{$\begin{array}{l}\text { 12. Smoke from substances such as wood, dung, bushes, coal } \\
\text { burned for heating and cooking at home may cause COPD. }\end{array}$} \\
\hline \multicolumn{6}{|l|}{$\begin{array}{l}\text { 13. The deficiency of vitamin A, C and E may play a role in the } \\
\text { development of COPD. }\end{array}$} \\
\hline \multicolumn{6}{|l|}{ 14. Alcohol use may play a role in the development of COPD. } \\
\hline \multicolumn{6}{|l|}{ 15. Although rare, some people may genetically develop COPD. } \\
\hline \multicolumn{6}{|l|}{$\begin{array}{l}\text { 16. Although patients are in the risk group, they may not have } \\
\text { complaints. }\end{array}$} \\
\hline \multicolumn{6}{|l|}{$\begin{array}{l}\text { 17. The most important complaints of the patients are cough and } \\
\text { sputum production. }\end{array}$} \\
\hline \multicolumn{6}{|l|}{$\begin{array}{l}\text { 20. Influenza and pneumonia vaccines are needed to prevent from } \\
\text { COPD. }\end{array}$} \\
\hline
\end{tabular}

$(22.9 \%)$ and $14(2.6 \%)$, respectively. The social-demographics and smoking characteristics of participants were detected in Section A and summarized in Table 2.

In Section B, all 531 participants were asked the question "Have you ever heard the term of COPD?". Four hundred ninety $(92.3 \%)$ of the participants answered this question as "YES". Considering the age range, the participants in the age range of 40-49 years had a statistically significant higher rate with the number and percentage of $117(23.87 \%)(p=0.039)$. According to smoking status, the moderate group (10-30 p/y) had significantly higher values and percentage of 246 and $50.2 \%$ ( $p<0.001)$. When taking education status into consideration, in all education levels, the percentage of answering as "YES" was higher compared to the participants answering as "NO" and the statistically prominent number and percentage of 170 and $34.69 \%$ was determined at primary/secondary school graduate $(p=0.004)$ respectively. The general characteristics of those who heard and did not hear the term of COPD were summarized in Table 3.

After the question "Have you heard of COPD?", the second question "Do you know what COPD is?" was asked to all participants. Four hundred twenty-four of 490 participants who said they heard about COPD stated that they had information about COPD. That is, a total of 107 participants stated that they did not know what COPD was.

The predicted symptoms of COPD and primary learning resource of COPD were also evaluated in Section B (Table 4). Dyspnea was described as the first most predicted symptom of COPD by 452 of the participants. In the disease-symptom pairing related to COPD, the symptoms were listed by frequency of response as dyspnea (87.1\%), sputum (79.6\%), cough $(67.8 \%)$, wheezing $(64.7 \%)$, tiredness $(54.5 \%)$, chest pain $(45.7 \%)$ and weight loss (30.4\%). 


\begin{tabular}{|c|c|c|c|c|}
\hline & & $\begin{array}{l}\text { Man } \\
n=343 \\
(64.5 \%)\end{array}$ & $\begin{array}{l}\text { Woman } \\
n=188 \\
(35.5 \%)\end{array}$ & $\begin{array}{l}\text { All patients } \\
n=531 \\
(100 \%)\end{array}$ \\
\hline \multicolumn{2}{|c|}{ Age (mean years $\pm S D$ ) } & $42.8 \pm 16.8$ & $44.3 \pm 12.3$ & $43.4 \pm 15.4$ \\
\hline \multicolumn{2}{|l|}{ BMI (mean $\pm S D)$} & $26.4 \pm 5.3$ & $25.8 \pm 4.5$ & $26.2 \pm 5.1$ \\
\hline \multicolumn{2}{|c|}{ Smoking pack-year (mean $\pm S D$ ) } & $25.9 \pm 19.4$ & $23.9 \pm 16.4$ & $25.3 \pm 18.4$ \\
\hline \multirow{3}{*}{$\begin{array}{l}\text { Education status* } \\
(\mathrm{n}, \%)\end{array}$} & Pri./Sec. school & $126(64.6 \%)$ & $69(35.4 \%)$ & $195(37.2 \%)$ \\
\hline & High school & $99(58.6 \%)$ & $70(41.4 \%)$ & $169(32.3 \%)$ \\
\hline & University & $110(72.4 \%)$ & $42(27.6 \%)$ & $152(29 \%)$ \\
\hline \multirow{4}{*}{$\begin{array}{l}\text { Occupation status } \\
(\mathrm{n}, \%)\end{array}$} & Unemployed & $10(50 \%)$ & $10(50 \%)$ & $20(4 \%)$ \\
\hline & Soldier & $17(100 \%)$ & - & $17(3.4 \%)$ \\
\hline & Retired & $51(71.8 \%)$ & $20(28.2 \%)$ & $71(14.3 \%)$ \\
\hline & Housewife & - & $92(100 \%)$ & $92(18.6 \%)$ \\
\hline \multirow{3}{*}{$\begin{array}{l}\text { Smoking status } \\
(\mathrm{n}, \%)\end{array}$} & Mild & $84(71.8 \%)$ & $33(28.2 \%)$ & $117(22.04 \%)$ \\
\hline & Moderate & $144(56.2 \%)$ & $112(43.8 \%)$ & $256(48.2 \%)$ \\
\hline & Severe & $115(72.8 \%)$ & $43(27.2 \%)$ & $158(29.76 \%)$ \\
\hline \multirow{3}{*}{$\begin{array}{l}\text { FTND level } \\
(n, \%)\end{array}$} & Mild & $34(56.7 \%)$ & $26(43.3 \%)$ & $60(11.5 \%)$ \\
\hline & Moderate & $200(70.2 \%)$ & $85(29.8 \%)$ & $285(54.6 \%)$ \\
\hline & Severe & $100(56.5 \%)$ & 77 (43.5\%) & 177 (33.9\%) \\
\hline
\end{tabular}

The participants were also asked for the resource of their information about COPD. Media (television/newspaper) was the first most popular information resource (46.7\%). The highest percentage of doctors as an information resource was present at the participants aged over 60 years with the percentage of $25.9 \%$ (Table 4). The distribution of participants' information resources by demographic and cigarette addiction status were summarized in Table 4.

In Section $\mathrm{C}$ of the study, a COPD awareness questionnaire with 20 question was applied to the participants (Table 1). The distribution of the answers given to the questions was evaluated. The first three questions confirmed with the highest percentage by men and women were the $9^{\text {th }}, 7^{\text {th }}$ and $19^{\text {th }}$ questions with the percentages of $86.3 \%, 82.5 \%, 79.6 \%$ and $86.2 \%, 80.9 \%$ and $78.2 \%$, respectively.

Confirmation rates of the participants to the question episodes of 'Perception', 'Knowledge', 'Acceptance' and 'Expectation' were also evaluated. The mean numbers and percentages of perception, knowledge, acceptance and expectation questions answered as agreed by all participants were respectively 361.6 (68.1\%), 281.6 (53.02\%), 381.8 (71.88\%) and 250.2 (47.14\%). Considering the percentages of survey explained above, the acceptance was detected as a prominent concept at current smokers on COPD awareness and perception, knowledge and expectation followed acceptance.

According to the answers given to the questions of survey, the total COPD Awareness Survey Score of the participants was calculated. Considering the scores of the survey, the mean score was $77.5 \pm 7.5$ in all participants, $76.7 \pm 6.9$ in females and $77.9 \pm 7.8$ in males. Correlations were investigated to determine whether there was a relationship between the COPD awareness score and demographic, social and clinical data. Possible correlations between awareness scores with age, BMI, cigarette package-year $(p / y)$, education level, duration of smoking, and FTND score of participants were assessed. We observed a positive significant correlation between COPD awareness score with cigarette package/year $(p=0.023, r=0.099)$.

According to the mean $\pm S D$ results of the normally distributed results, the participants' scores were divided into 3 main groups; "Poor Awareness", "Good Awareness" and "Very Good Awareness". Those whose total scores were within the "mean score $\pm S D$ ' range were defined as "Good Awareness", those with higher scores than the 'mean score+SD' upper limit as "Very Good Awareness" and the those with a lower score than the 'mean score-SD' as "Poor Awareness". Hereby, the groups "Poor Awareness", "Good Awareness" and "Very Good Awareness" 


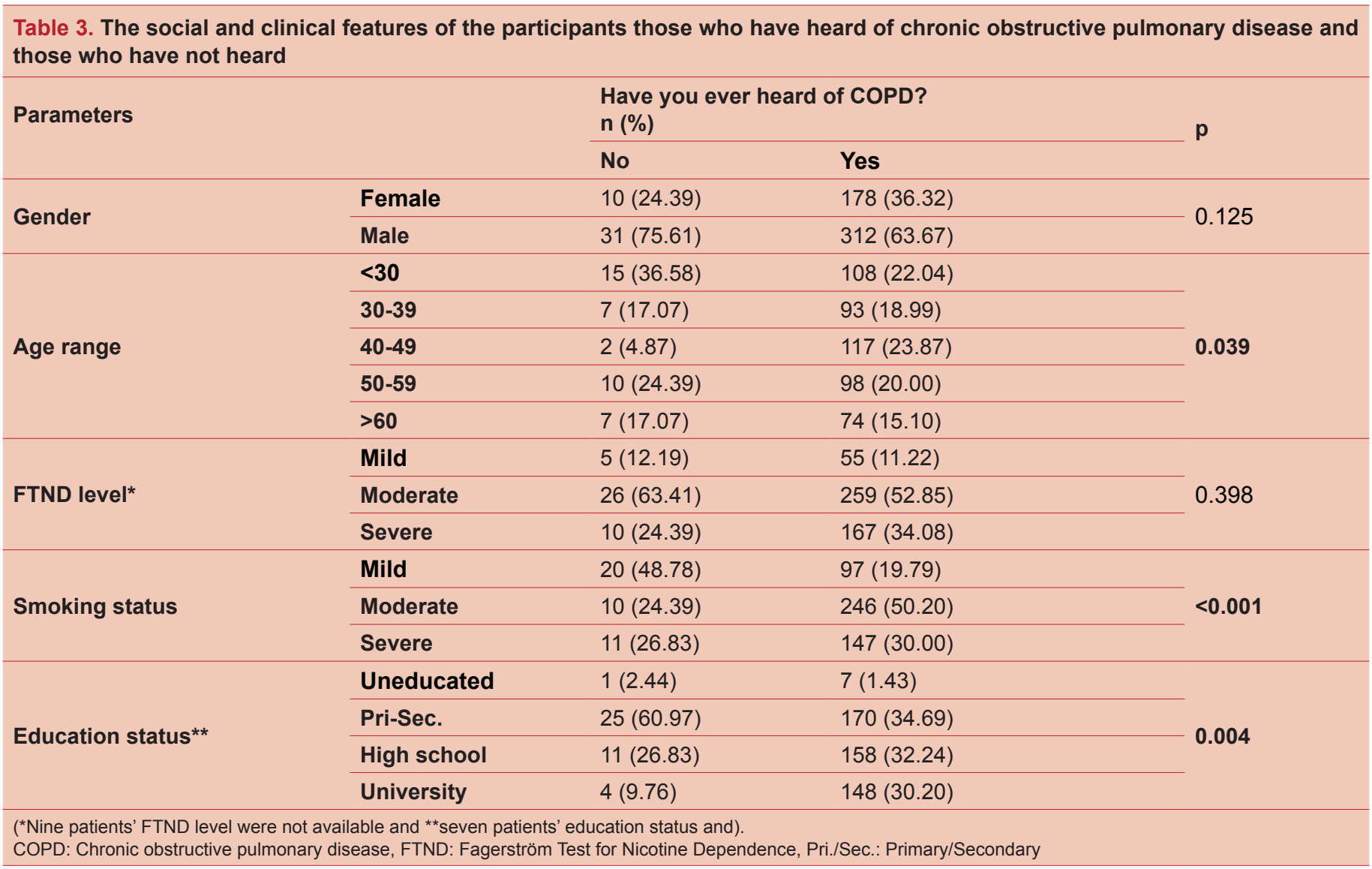

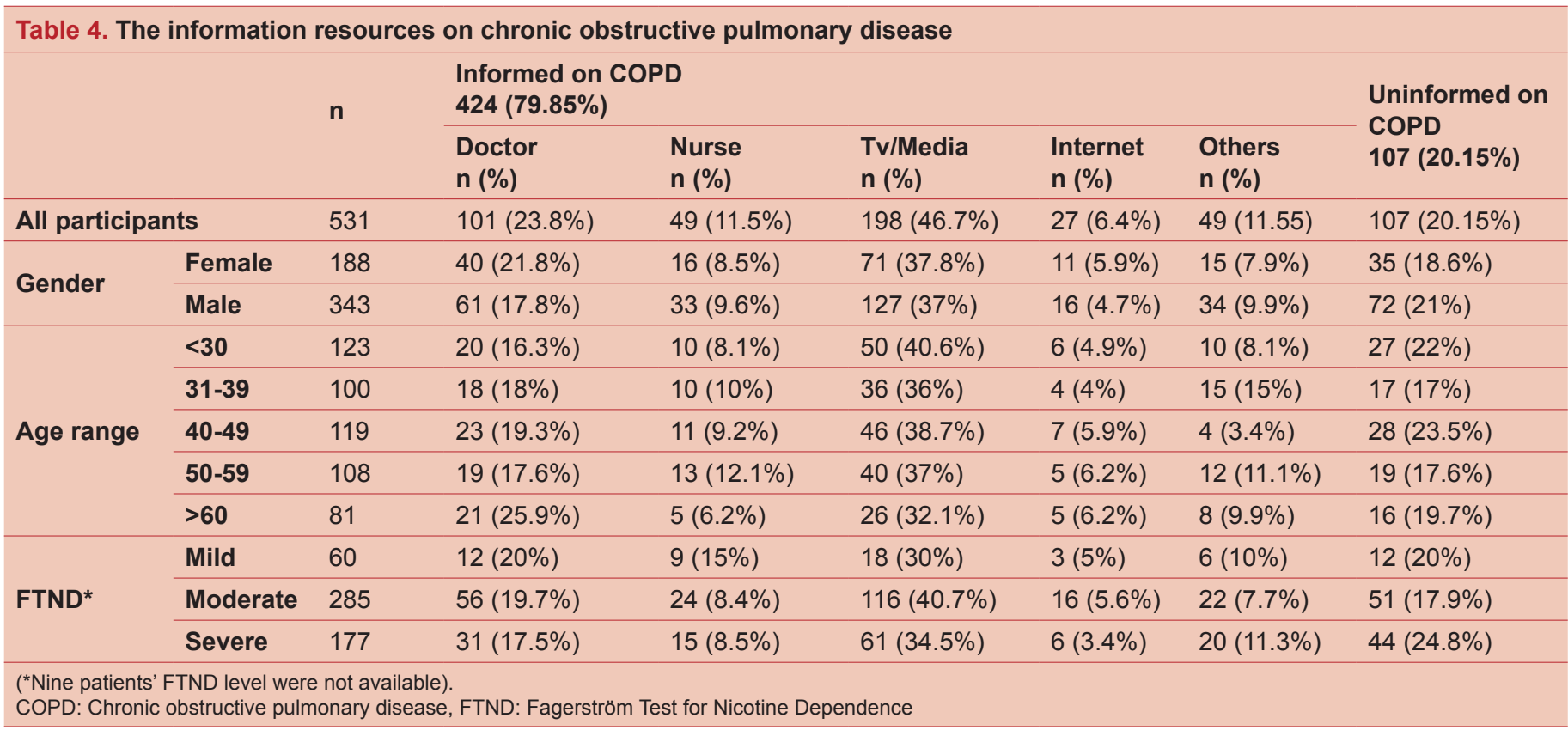

defined the participants with total survey score of "0-69", "7085" and "86-100", respectively. The numbers and percentages of "Poor Awareness", "Good Awareness" and "Very Good Awareness" leveled groups were 211 (39.75\%), 299 (56.3\%), and $21(3.95 \%)$, respectively. At the end of the awareness assessment, the proportion of "Very Good Awareness" was found to be $3.97 \%(n=21)$ in the entire population. "Very Good Awareness" rates according to the education levels were $0 \%, 15 \%, 30 \%$ and $55 \%$, respectively. Although there was no statistical significance, it was found that awareness of COPD increased as the level of education increased (Table 5). 


\begin{tabular}{|c|c|c|c|c|c|}
\hline & \multicolumn{4}{|c|}{ COPD awareness score $(n, \%)$} & \multirow{2}{*}{$\mathbf{p}$} \\
\hline & & Poor Awareness & Good Awareness & Very Good Awareness & \\
\hline \multirow[t]{2}{*}{ FTND level* } & Moderate & $114(40 \%)$ & $158(55.4 \%)$ & $13(4.6 \%)$ & \multirow[t]{2}{*}{0.176} \\
\hline & Severe & $65(36.7 \%)$ & $108(61 \%)$ & $4(2.3 \%)$ & \\
\hline \multirow[t]{2}{*}{ Smoking status } & Moderate & $107(41.8 \%)$ & $140(54.7 \%)$ & $9(3.5 \%)$ & \multirow[t]{2}{*}{0.830} \\
\hline & Severe & $57(36.1 \%)$ & $94(59.5 \%)$ & $7(4.4 \%)$ & \\
\hline \multirow{3}{*}{ Education status** } & Uneducated & $2(25 \%)$ & $6(75 \%)$ & - & \multirow{3}{*}{0.176} \\
\hline & Pri.-Sec. & $80(41 \%)$ & $112(57.4 \%)$ & $3(1.5 \%)$ & \\
\hline & High school & $67(39.6 \%)$ & $96(56.8 \%)$ & $6(3.6 \%)$ & \\
\hline \multirow{5}{*}{ Age range } & $<30$ & $50(40.7 \%)$ & $67(54.5 \%)$ & $6(4.9 \%)$ & \multirow{5}{*}{0.445} \\
\hline & $30-39$ & $48(48 \%)$ & $49(49(\%)$ & $3(3 \%)$ & \\
\hline & $40-49$ & $50(42 \%)$ & $66(55.5 \%)$ & $3(2.5 \%)$ & \\
\hline & $50-59$ & $34(31.5 \%)$ & $69(63.9 \%)$ & $5(4.6 \%)$ & \\
\hline & $>60$ & $29(35.8 \%)$ & $48(59.3 \%)$ & $4(4.9 \%)$ & \\
\hline
\end{tabular}

\section{Discussion}

COPD is a chronic and progressive airway disease. It still ranks the $4^{\text {th }}$ among all causes of death in the world, and its frequency is expected to increase further in the coming years. Given that smoking is the most important predictive risk factor for COPD, it would not be wrong to say that it is a public health problem that can be prevented and controlled mostly. Despite all these definitive medical facts, the public awareness is still low, unfortunately. Individuals and patients cannot fully identify the disease and the name of COPD; moreover, patients express their illnesses with wrong diagnoses such as asthma, bronchitis etc. On the other hand, there are problems in conceptual perception regarding COPD treatment. Most patients perceive the inhaler bronchodilator treatments that are prescribed to them only as "air' and believe that they are not given any medications. This unconsciousness also adversely affects patients' compliance to treatment. Given all these facts, it is obvious that raising public awareness about COPD is a public health responsibility.

Considering the COPD Awareness Survey Scores of participants with the mean points of $77.5 \pm 7.5$ points, it was found to be corresponded to "Good Awareness Level".

In Turkey, such as many countries in the world, the perception and knowledge of COPD is thought to have increased in recent years thanks to smoking restrictions, smoke-free airspace applications, very serious control mechanisms related to the sale and consumption of tobacco products, informative messages added on cigarette packs, public spots, smoking cessation polyclinics, social programs and trainings. In our clinical practice, the feedbacks received from individuals and patients have revealed the dominant idea that social knowledge about COPD has increased, but of course, more concrete data are needed to turn this idea into an objective scientific thesis. At this point, based on the references taken from previous studies, it is commonly accepted that face-to-face interviews and objective surveys give very useful results. In screening studies for COPD awareness, positive changes in awareness rates have been observed in the last 20 years. However, these positive developments differ considerably among countries.

In a Spain-based study, which is one of the comparative old examples of such studies, awareness rates for 2012 and 2002 were compared, and it was found that COPD awareness increased from $8.6 \%$ to $17.0 \%$ in the general population $(24,21)$. In a telephone survey study conducted in Spain, only $8.6 \%$ of 6758 people knew COPD (24). Smokers were reached in a hybrid survey study conducted in Canada in 2010 . While $72 \%$ of active smokers knew about cancer and $56 \%$ knew about sleep apnea, only $36 \%$ said they had heard of COPD before (25). However, when compared to the Canada's COPD awareness rate in 2005 , the increase from $17 \%$ to $36 \%$ can be considered as a partial positive development $(26,27)$.

In a French study conducted in 2011 , only $8 \%$ individuals knew the term of COPD and $66 \%$ associated the term COPD 
with respiratory disease in the population aged 40 to 75 years (17). We see that higher awareness rates are starting to be identified as we come to more recent times. For example, in a Danish study, published in 2018, including 1002 participants, the percentages of knowing the symptoms of COPD were $86.4 \%, 89.2 \%, 81.5 \%$ and $85.1 \%$ at smokers, ex-smokers, non-smokers and all participants, respectively (28). In GARD study carried out in Turkey in 2013, COPD awareness of the general population was found to be $49.6 \%$ (22). Unfortunately, these positive developments have not been detected in studies in Korea. In Korean studies, awareness of COPD among smokers was between $0.4 \%$ and $26.5 \%(15,29)$. In this study, we aimed to investigate this awareness in smokers, which was the main target group for the development and prevention of COPD. The data we obtained through the face-to-face interviews and questionnaire study gave us very positive results on the awareness of COPD in active smokers, the highest risk population for COPD.

The mean age of the applicants to quit smoking was $43.4 \pm 15.4$ years, which represented an age group suitable for the early diagnosis of COPD $(1,4)$. Considering the gender distribution, men made up the majority. This situation has been interpreted in relation to the higher incidence of smoking in men in our country (9). At the evaluation of educational status, the positive relationship between the desire of quitting smoke and the education level of smokers was stood out. Our examination of nicotine dependency rates of those who accepted to quit smoking and participate in our study showed us that individuals with low and high mean FTND scores were in the minority and most of the participants had moderate FTND scores. In other words, it can be said that individuals with moderate FTND scores are more enthusiastic about quitting smoking.

In this current study, the high percentage of "YES" answers $(92.3 \%)$ given by the smokers to the question of "Have you ever heard of COPD?" is a significant indicator of high awareness to COPD as the beneficial result of anti-smoking strategies like an establishing smoking cessation outpatient clinics. This rate is significantly higher than the rates reported in some studies involving the entire population or smokers only. Different mechanisms may have played role here. The first and the most hopeful is the significantly increased awareness of COPD in the community, especially among smokers. This increase in hearing COPD can be considered as an indicator of that anti-smoking strategies are working, although reducing smoking rates is the main goal of these strategies. The second possible mechanism is that the population of this study consists of participants who applied to the smoking cessation unit of a tertiary hospital voluntarily, reside in the capital and have a high awareness of receiving health care. This participant profile may not fully reflect the countryside. In other words, when it spreads to the general public, this awareness rate will probably reduce. In a survey conducted in 2016 in Turkey involving active smokers, it was reported that only $34 \%$ of the population recognized the term "COPD" as a "pulmonary disease" (23). In addition, since it covers only enthusiasts for smoking cessation, but not all smokers, it can be thought that the participants are a high perception population about the smoking-related health problems.

While there is no significant difference in terms of gender distribution and FTND levels between those who have heard of COPD and those who have not heard before, there was a significant difference between age groups, smoking intensity and education levels (Table 3). Similarly, in the GARD study conducted in Turkey, there was no significant difference between the genders and the awareness rates decreasing in older age (22). In this current study, it was found that those with a low intensity of smoking were unaware of the disease more often. While $66.93 \%$ of those who had heard of the disease before were at least high school graduates, only $36.59 \%$ of those who had never heard before were at least high school graduates. The education levels of the participants seem to be very decisive in this regard.

Among the resources of information about COPD, TV/media was the top rated for all participants. While the TV/media sources became more prominent in the younger age group, physicians came to dominant for with advancing age as the information resources. This is a result that supports the view that personal information acquisition sources are closely related to social life habits. This result should be taken into account in the future educational activities for the younger age group who are close to the media. It can be interpreted that family physicians should show more sensitivity to COPD in middle and older age groups. Similarly, in the results of Spain and Korea, TV was shown as the most common source of information $(15,21)$.

When we analyzed the answers given to our COPD awareness survey questions, we found that the highest awareness was in the 'acceptance' questions and the lowest awareness was in the 'expectation' questions. This concept is very specific to the current study and no evident mentioning on this concept was present in the concerning studies (1429). While awareness of smokers about risk factors in the development of COPD was higher, levels of knowledge about prevention of COPD and follow-up of the disease were found lower. This shows that smokers have mostly heard of COPD, but they need to know better about the disease.

We observed a significant positive correlation between COPD awareness score and cigarette p/y levels. We interpret this relationship that awareness of COPD and therefore concerns about the disease have increased in intensive smokers over time, perhaps due to the early onset of symptoms, perhaps from the warnings of people in their close circles, or as a result of seeing the stimulating relatives on cigarette packs more 
frequently. In general, we also observed a close relationship between COPD awareness and education level. The frequency of 'very good awareness' was encountered most frequently among participants who were university graduates. According to the total score of COPD awareness survey, 17 of the 20 participants evaluated in the 'very good awareness' group were at least high school graduates. Increasing the level of education should be considered as one of the points of diffraction in social struggle with COPD. The fact that our study was conducted in volunteers who applied to smoking cessation units can be considered as a subjective limitation.

\section{Conclusion}

The awareness level of COPD among smokers admitted to pulmonary medicine department was detected as "Good", and this "Good" level is predicted to be associated with the publicly sponsored broad anti-smoking campaigns including smoking cessation outpatient clinics offering free service.

The high-level acceptance of the participants on COPD Awareness encouraged us to abolish COPD in Turkey and all around the world. Since high percentages of positive answers given to admission questions compared to other sections were prominent in the survey, it is advisable to increase the awareness level of smokers should be set as a priority target in policies to combat COPD. Thus, smoking rates and COPD frequency could be reduced together. More general data can be obtained with this type of study to be carried out by spreading to the general public. The smoker part of the public must be taken into consideration to struggle with the smoking pandemic. Especially, campaigns aiming to correct the acceptance of smokers would increase the success of smoking cessation strategies. We believe that current study and the subsequent ones to be carried out in this concept from now on will guide the fight against smoking and COPD.

\section{Ethics}

Ethics Committee Approval: Ethics committee approval was received for this study from the Ethics Committee of Gülhane Training and Research Hospital with the number of 18/111 at April 24, 2018.

Informed Consent: Written informed consent was obtained from patients who participated in this study.

Peer-review: Externally peer-reviewed.

\section{Authorship Contributions}

Surgical and Medical Practices: Y.A., O.S., Concept: Y.A., O.S., Design: Y.A., N.Ö., Data Collection or Processing: A.Ç., Y.A., Analysis or Interpretation: D.D., C.T., Writing: Y.A., N.Ö.

Conflict of Interest: No conflict of interest was declared by the authors.
Financial Disclosure: The authors declared that this study has received no financial support.

\section{References}

1. Global Initiative for Chronic Obstructive Lung Disease. Global strategy for the diagnosis, management, and prevention of chronic obstructive pulmonary disease. Updated 2020 [Internet]. Bethesda, MD: Global Initiative for Chronic Obstructive Lung Disease; 2020. Available from: http://www.goldcopd.org.

2. Lozano R, Naghavi M, Foreman K, et al. Global and regional mortality from 235 causes of death for 20 age groups in 1990 and 2010: a systematic analysis for the Global Burden of Disease Study 2010. Lancet. 2012;380:2095-2128.

3. Mathers $C D$, Loncar D. Projections of global mortality and burden of disease from 2002 to 2030. PLoS Med. 2006;3:442.

4. Diaz-Guzman E, Mannino DM. Epidemiology and prevalence of chronic obstructive pulmonary disease. Clin Chest Med. 2014;35:7-16.

5. Buist AS, McBurnie MA, Vollmer WM, et al. International variation in the prevalence of COPD (the BOLD Study): a population-based prevalence study. Lancet. 2007;370:741750.

6. Løkke A, Fabricius PG, Vestbo J, Marott JL, Lange P. Forekomst af kronisk obstruktiv lungesygdomi København: resultater fra Østerbroundersøgelsen. Ugeskr Læger. 2007;169:3956-3960.

7. Løkke A, Hilberg O, Tønnesen P, Ibsen R, Kjellberg $\mathrm{J}$, Jennum P. Direct and indirect economic and health consequences of COPD in Denmark: a national registerbased study: 1998-2010. BMJ Open. 2014;4:e004069.

8. Lundbäck B, Lindberg A, Lindström M, et al. Not 15 But $50 \%$ of smokers develop COPD? - report from the obstructive lung disease in Northern Sweden studies. Respir Med. 2003;97:115-122.

9. National Household Health Survey - Prevalence of Noncommunicable Disease Risk Factors in Turkey 2017 (STEPS). In: Üner S, Balcılar M, Ergüder T, eds. World Health Organization Country Office in Turkey: Ankara; 2018.

10. Pinnock $H$, Kendall M, Murray SA, et al. Living and dying with severe chronic obstructive pulmonary disease: multi-perspective longitudinal qualitative study. BMJ. 2011;342:142.

11. Frank TL, Hazell ML, Linehan MF, Frank PI. The diagnostic accuracies of chronic obstructive pulmonary disease (COPD) in general practice: the results of the MAGIC (Manchester Airways Group Identifying COPD) study. Prim Care Respir J. 2006;15:286-293.

12. Løkke A, Ulrik CS, Dahl R, et al. Detection of previously undiagnosed cases of COPD in a high-risk population identified in general practice. COPD. 2012;9:458-465. 
13. Lundbäck B, Gulsvik A, Albers $M$, et al. Epidemiological aspects and early detection of chronic obstructive airway diseases in the elderly. Eur Respir J Suppl. 2003;40:3-9.

14. Mun SY, Hwang YI, Kim JH, et al. Awareness of chronic obstructive pulmonary disease in current smokers: a nationwide survey. Korean J Intern Med. 2015;30:191-197.

15. Seo JY, Hwang YI, Mun SY, et al. Awareness of COPD in a high risk Korean population. Yonsei Med J. 2015;56:362367.

16. Sayiner A, Alzaabi A, Obeidat NM, et al. Attitudes and beliefs about COPD: data from the BREATHE study. Respir Med. 2012;106(Suppl 2):60-74.

17. Roche N, Perez T, Neukirch F, et al. High prevalence of COPD symptoms in the general population contrasting with low awareness of the disease. Rev Mal Respir. 2011;28:5865.

18. Asai M, Tanaka T, Kozu R, Kitagawa C, Tabusadani M, Senjyu $\mathrm{H}$. Effect of a chronic obstructive pulmonary disease (COPD) intervention on COPD awareness in a regional city in Japan. Intern Med. 2015;54:163-169.

19. Omori H, Yoshimoto D, Kumar M, Goren A. Prevalence, awareness, characteristics, and health outcomes associated with COPD at-risk status among adults in Japan. Expert Rev Pharmacoecon Outcomes Res. 2015;16:501512.

20. Lou P, Zhu Y, Chen P, et al. Vulnerability, beliefs, treatments and economic burden of chronic obstructive pulmonary disease in rural areas in China: a cross-sectional study. BMC Public Health. 2012;12:287.

21. Soriano JB, Calle M, Montemayor T, Alvarez-Sala JL, Ruiz-Manzano J, Miravitlles M. The general public's knowledge of chronic obstructive pulmonary disease and its determinants: Current situation and recent changes. Arch Bronconeumol. 2012;48:308-315.
22. Yıldız F, Bingöl Karakoç G, Ersu Hamutçu R, Yardım N, Ekıncı B, Yorgancıoğlu A. The evaluation of asthma and COPD awareness in Turkey (GARD Turkey ProjectNational Control Program of Chronic Airway Diseases). Tuberk Toraks. 2013;61:175-182.

23. Türkmen L, Bali EB, Cihan P, Bakır B. Evaluation of Awareness of Chronic Obstructive Respiratory Disease in the Population Addicted to Cigarette. Journal of Adnan Menderes University Health Sciences Faculty. 2018;2:4754.

24. Miravitlles M, de la Roza C, Morera, et al. Chronic respiratory symptoms, spirometry and knowledge of COPD among general population. Respir Med. 2006;100:19731980.

25. Walker SL, Saltman DL, Colucci R, Martin L; Canadian Lung Association Advisory Committee. Awareness of risk factors among persons at risk for lung cancer, chronic obstructive pulmonary disease and sleep apnea: A Canadian population-based study. Can Respir J. 2010;17:287-294.

26. Chronic Obstructive Pulmonary Disease (COPD) in Canada. Last accessed date: June 10, 2010. Accessed at: http://www.lung.ca/media-medias/news-nouvellese. phpid $=98$

27. National COPD Report card 2005. Last accessed date: October 29, 2010. Accessed at: www.lung.ca/_ resources/2005.copd_reportcard.pdf

28. Sikjær MG, Hilberg O, Fløe A, Dollerup J, Løkke A. Lack of awareness towards smoking-related health risks, symptoms related to COPD, and attitudinal factors concerning smoking: an Internet-based survey conducted in a random sample of the Danish general population. Eur Clin Respir J. 2018;5:1506235.

29. Mun SY, Hwang YI, Kim JH, et al. Awareness of chronic obstructive pulmonary disease in current smokers: a nationwide survey. Korean J Intern Med. 2015;30:191-197. 